\title{
Immunomodulator effect of Robusta Lampung coffee extract (Coffee Canephora Var Robusta) in layer chicken infected with Salmonella enteritidis bacteria
}

\author{
Dahliatul Qosimah ${ }^{* 1}$, Djalal Rosyidi ${ }^{2}$, Lilik Eka Radiati ${ }^{2}$, Indah Amalia Amri ${ }^{1}$, Dodik \\ Prasetyo $^{3}$, Fajar Shodiq Permata ${ }^{4}$, Ma A Guiang Beltran ${ }^{5}$, A. Aulanni'am ${ }^{6}$ dan Agri Kaltaria \\ Annisa $^{7}$ \\ ${ }^{1}$ Laboratory of Microbiology and Immunology, Faculty of Veterinary Medicine, Brawijaya \\ University \\ ${ }^{2}$ Laboratory of Animal Product Technology, Faculty of Animal Husbandry, Brawijaya \\ University \\ ${ }^{3}$ Animal Clinic, Faculty of Veterinary Medicine, Brawijaya University \\ ${ }^{4}$ Laboratory of Anatomy Pathology, Faculty of Veterinary Medicine, Brawijaya University \\ ${ }^{5}$ College of Veterinary Medicine, Tarlac Agricultural University, Camiling, Tarlac, \\ Philippines \\ ${ }^{6}$ Laboratory of Biochemical, Faculty of Veterinary Medicine, Brawijaya University, \\ Indonesia \\ ${ }^{7}$ Laboratory of Pharmacology, Faculty of Veterinary Medicine, Brawijaya University
}

Submitted: 30 September 2019, Accepted: 18 February 2020

\begin{abstract}
Salmonellosis that attacks poultry, caused by Salmonella enteritidis is a cause of food borne disease in zoonotic humans. Treatment of this disease uses antibiotics but if used irrationally it can result in the emergence of multi-drug resistant bacteria. At present many treatments use herbs which are considered to reduce the negative effects of antibiotics and are environmentally friendly, one of which is coffee. Green coffee is considered to have many active ingredients such as chlorogenic acid (CGA), alkaloids, tannin, polyphenols and polysaccharides which are useful as antimicrobial, anti-inflammatory and enhances the body's immune system. The study used 60 heads ISA Brown day-old chicks (layer strain) chickens artificially infected with $S$. enteritidis bacteria with concentration of $10^{8} \mathrm{CFU} / \mathrm{ml}$, consisting of negative controls (healthy chickens, without coffee, positive control (chickens were given), T1, T2 and T3 was given different doses of coffee extract with $500 \mathrm{mg} / \mathrm{kg} \mathrm{BW}, 1000 \mathrm{mg} / \mathrm{kg} \mathrm{BW}$ and $1500 \mathrm{mg} \mathrm{kg} \mathrm{BW}$, respectively. The treatments with coffee extracts were given on days 315 , then infected with $0.5 \mathrm{ml}$ bacteria on day 16 and 60 chickens were necropsied at day 18 for histopathology. Data on relative levels of CD8 Tc cells were calculated using the flowcytometer test and analyzed quantitatively using the One Way ANOVA with a confidence level of $95 \%$ while the jejunum histopathology was observed using a microscopy and analyzed descriptively. Results showed that Robusta coffee extract from Lampung can act as an antibacterial by increasing CD8 $+\mathrm{T}$ cells and repairing jejunum histopathology.
\end{abstract}

Keywords: Green coffee, lymphocyte cells, salmonellosis, zoonoses

\footnotetext{
*Corresponding Author: dahliatulqosimah@gmail.com
} 


\section{INTRODUCTION}

Salmonella enteritidis serovar enteritidis is a serotype that is often isolated from gastroenteritis due to consuming contaminated food (animal products) in humans avarages $75 \%$ caused by contaminated food products derived from beef, pork, poultry and eggs. Chicken is the largest reservoir host for Salmonella enteritidis (Shah et al., 2012). Poultry are often infected through consumption of contaminated feed on farms or during slaughter and processing. Salmonella infection usually starts through ingestion, and is followed by colonization in the intestine.

After colonization, Salmonella is able to penetrate the mucosal epithelium which results in systemic infections (Muna et al., 2016). Young chickens $<2$ weeks old often get gastroenteritis and systemic diseases with various mortality rates. In contrast, most adult chickens are carriers of $S$. enteritidis, without showing clinics, transmitted through feces excreted. In young broilers it can cause high mortality so it must be culling from flock (Shah et al., 2012).

Natural products have long been recognized as an important source of effective drug therapy. Of the 520 new drugs were approved in 1983 and 1994, 39\% came from natural products and $60-80 \%$ serves as an antibacterial and anticancer drugs (Barbosa-Filho et al., 2006). Coffee is a mixture of over a thousand phytochemicals such as alkaloids, phenolic compounds, vitamins, carbohydrates, lipids, minerals and nitrogen compounds. Coffee has multifunctional properties as a food additive and nutraceutical namely chlorogenic acid, coffee has the effect of being antiinflammatory, anti-oxidant, anti-dyslipidemia, anti-obesity, and cardiovascular disease, which can be used for the treatment and prevention of metabolic syndrome and related disorders.

On the other hand, as a food additive, coffee has antimicrobial activity against various microorganisms, inhibits lipid peroxidation, and can function as a prebiotic (Saeed et al., 2019). This research is very interesting because until now there has been no research on the use of coffee extract for chicken health performance, especially in the starter phase chicken. Poultry is the animal products as a source of high protein in humans. Disease in humans can be derived from poultry. Production of high laying hens can be monitored early so that the results of this study are expected to be a reference for further research on chickens using coffee. This study uses chicken layer strain ISA brown 1 day old and has obtained the Ethical Clearance No. 773-KEP-UB from the Bioscience Laboratory of Universitas Brawijaya.

Coffee extracts manufacture, testing Phytochemicals and LCMS (Liquid chromatography-mass spectrometry)

The coffee extraction was carried out at UPT Materia Medika, Batu, Indonesia using 90\% ethanol. 414 grams of Lampung Robusta coffee soaked with $1500 \mathrm{ml}$ of ethanol $90 \%$ in a jar and then tightly closed and carried out a shaker with a speed of 50 rpm. Soaking was done three times. The filtrate was evaporated using a rotatory evaporator. The extraction of liquid chocolate used for the study.

\section{Experimental animal design}

Chickens were placed in cages and given feed and drink in ad libitum. Chickens were given standard commercial feed Charoen Pokphand 511-bravo with nutritional content that is Rough Protein 2123\% - 5-8\% Fat - Rough Fiber 3-5\% - 4-7\% Ash. Research used 5 treatments and 4 replications with three birds per replications consisting of a negative control (healthy chicken, without any coffee), positive control (chickens infected with $S$. enteritidis bacteria at concentrations of $10^{8} \mathrm{CFU} / \mathrm{ml}$ ), T1 (chicken given coffee a dose of 500 $\mathrm{mg} / \mathrm{kg}$ bw and infected with $S$. enteritidis bacteria with a concentration of $10^{8}$ $\mathrm{CFU} / \mathrm{ml}$ ), T2 (chickens were given coffee with a dose of $1000 \mathrm{mg} / \mathrm{kg}$ bw and infected with $S$. enteritidis bacteria with a 
concentration of $10^{8} \mathrm{CFU} / \mathrm{ml}$ ) and $\mathrm{T} 3$ (chickens were given coffee dosage 1500 $\mathrm{mg} / \mathrm{kg}$ bw and infected with $S$. enteritidis with a concentration of $10^{8} \mathrm{CFU} / \mathrm{ml}$ ). Supplements in chickens aged 1,5 and 11 days were given vitamins to prevent stress, at Day 4, an ND-IB live vaccine was administered, and at Day 10, ND G7B vaccine and $\mathrm{AI}$ H5N1 subtype were given. Chickens were fasted for 10 hours before being given coffee extract. Coffee extract were given to chickens at days 3-16 orally.

\section{Making bacterial suspension}

S.enteritidis bacteria grown in nutrient broth media and incubated at $37^{\circ} \mathrm{C}$ for $24 \mathrm{~h}$. Bacterial growth was measured its absorbance at a wavelength of $580 \mathrm{~nm}$ using a spectrophotometer and were further diluted to obtain a concentration of bacteria at $10^{8} \mathrm{CFU} / \mathrm{ml}$ (Mostafa et al., 2018). The bacterial suspension was given to the chickens orally with a volume of $0.5 \mathrm{ml}$ per chicken. Giving a bacterial infection using a feeding tube on the $16^{\text {th }}$ day. A necropsy performed on the $18^{\text {th }}$ day.

Examination number relative of $\mathrm{CD8}^{+} \mathrm{TC}$ cells

Cells isolated from the thymus were incubated with anti-CD8 + PE chicken antibody. Samples were incubated with antibodies, added with $1 \mathrm{ml}$ PBS and placed on the cuvette flowcytometer. The relative number of cells is calculated. The results obtained were processed with the BD cell quest ProT program (Kurnianingtyas et al., 2013).

\section{Histopathological examination of jejunum}

Chickens were killed through air embolism, then examination for jejunum intestine was done. The jejunum was washed with PBS, $10 \%$ formalin solution was added and histopathological preparations were made using hematoxylin and eosin staining ( $\mathrm{H} \& \mathrm{E}$ ) (Muna et al., 2016).

\section{Data analysis}

The number of $\mathrm{CD} 8^{+} \mathrm{Tc}$ cells were presented as mean \pm standard deviation (S.D). Statistical analysis for animal experiment was carried out using one-way ANOVA with an error level of 0.05 .

\section{RESULTS AND DISCUSSIONS \\ The active ingredient of Lampung coffee extract}

The active content of Lampung coffee extract using the phytochemical test shows the presence tannins and alkaloids. The LCMS Test results show chlorogenic acid (CGA). The main polyphenol in coffee is chlorogenic acid (CGA). CGA is an ester form of cinnamic acid and quinic acid, known as 5-O-caffeoylquinic acid (5-CQA) or 3-CQA. The largest form of CGA is 5caffeoylquinic acid (5-CQA) (Meng et al., 2013)

\section{Calculation of weight}

The results showed that the gain in weight of chicken on a negative control (healthy) higher than the positive control, which was expected since the chicken were infected with $S$. enteritidis bacteria. While the chickens fed the coffee extract at all doses showed a decrease in body weight compared to a negative chicken (unpublished data).

Commercial laying hens are genetically chosen that has the characteristics of contrafreeloading (the ability to adapt to choose the preferred feed) more active, and utilizes nutrients more efficiently so that the average metabolism of the energy produced is higher than broilers because the feed that enters the body is intended for production eggs are higher than weight gain (Buzala and Janicki, 2016). Commercial laying hens are genetically chosen that has the characteristics of contrafreeloading (the ability to adapt to choose the preferred feed) more active, and utilizes nutrients more efficiently so that the average metabolism of the energy produced is higher than broilers because the feed that enters the body is intended for production eggs are higher than weight gain (Buzala and Janicki, 2016).

CGA components have biological functions such as antibacterial, antioxidant, anti-carcinogenic, hypoglycemic, and 
hypolipidemic. The results of this study are consistent with those conducted by Meng et al. (2013), CGA is claimed to modulate glucose and lipid metabolism in vivo under conditions of abnormal genetic metabolism. While CGA, caffeine, and other polyphenol compounds in green coffee bean extract act to suppress weight gain, does not cause obesity and visceral fat deposition in mice. The mechanism of CGA in reducing blood lipids is most likely related to inhibition of lipid absorption and transformation through inhibition of intestinal absorption and liver cholesterol biosynthesis (Meng et al., 2013).

\section{Measurement of relative quantities of} $\mathrm{CD8}^{+} \mathrm{Tc}$ cell

The results showed that the relative number of $\mathrm{CD} 8^{+} \mathrm{Tc}$ cells in positive control (chicken infected with $S$. enteritidis bacteria) decreased, compared to the negative control group (healthy). All treatments showed comparable results compared to the negative control group. When compared with positive control, T1 showed a significant difference on the number of $\mathrm{CD}^{+} \mathrm{Tc}$ cells closer to negative control (Figure 1). This shows that administration of coffee extract at $\mathrm{T} 1$ group dose has increased the activation of $\mathrm{CD}^{+} \mathrm{Tc}$ cell effector cells.

$\mathrm{CD}^{+} \mathrm{Tc}$ cells are effector cells of the adaptive immune system to maintain longlasting protective immunity against intracellular bacteria, protozoa, and viruses. After reactivation by antigens, CD8 + Tc cells produce pro-inflammatory cytokines such as IFN-Y, and TNF- $\alpha$ for inflammatory activity (Narni-Mancinelli et al., 2007).

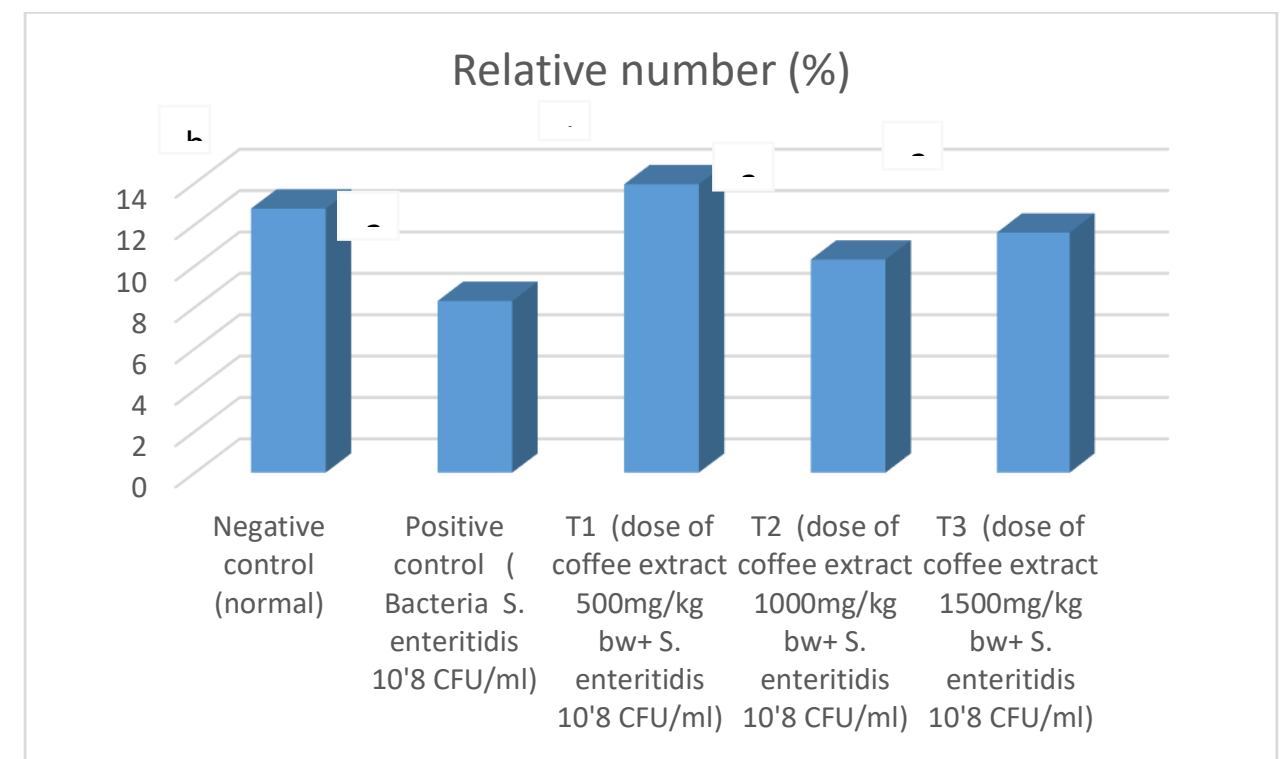

Figure 1. The number of CD $8+\mathrm{T}$ cells relative shows that there are differences among the treatments $(\mathrm{P}<0,05)$

During colon colonization inflammation occurs characterized by the entry of heterophils and macrophages which act as host immune systems against intracellular microbes such as Salmonella (Shah et al., 2012). S. enteritidis bacteria have the ability to survive in intestinal cells and penetrate to the mucosal epithelium, causing spread to organs, including the spleen, liver and reproductive tract. In the digestive system of birds, including the stomach has gastric acidity ( $\mathrm{pH}$ 2.6). Microbial killings by $\mathrm{CD}^{+} \mathrm{Tc}$ cells via MHC-peptide bonds: T-cell receptor interactions (TCR) cause lysis of target cells via pathways involving the release of apoptotic-inducing pore proteins, perforin, and granzymes secreted by $\mathrm{CD}^{+}$Tc cells (Jiang et al., 2003).

Granulysin (in contrast to granzymes) acts as a mediator of microbial killing through disruption of membrane 
permeability by damaging ionic interactions between positively charged amino acid residues and negatively charged phospholipids which result in the entry of fluids into the cytoplasm and death by osmotic lysis (Oykhman and Mody, 2010).

\section{Histopathological Examination of jejunum}

Histopathologic examination of the negative control (healthy chicken) show that the villi in the jejunum organs under normal conditions and elongated compared to the villi of the positive control (chickens infected bacteria $S$. enteritidis) appear shortening and erosion of the intestinal epithelium (Figure 2a and 2b). S. enteritidis bacteria can damage and make shortening of the intestinal villi. The length of villi plays a role in the expansion of the surface of nutrient absorption so that it influences weight gain. In the T1 and T2 (Figure $2 \mathrm{c}$ and $2 \mathrm{~d}$ ), the intestinal villi length and normal epithelium and goblet cell hyperplasia, while in T3 (Figure 2e), the intestinal villi were shorter than $\mathrm{T} 1$, erosion of epithelial and goblet cell hyperplasia. In the treatment of T2, the intestinal villi appear normal and elongated compared to treatment $\mathrm{T} 1$. Treatment $\mathrm{T} 1$ and $\mathrm{T} 2$ showed improvement of intestinal villi compared to positive control and T3. These results showed that the coffee extract at doses of 500 and 1000 $\mathrm{mg} / \mathrm{kg} \mathrm{BW}$ can improve intestinal integrity and increase the length of intestinal villi against damages of $S$. enteritidis bacteria infection.

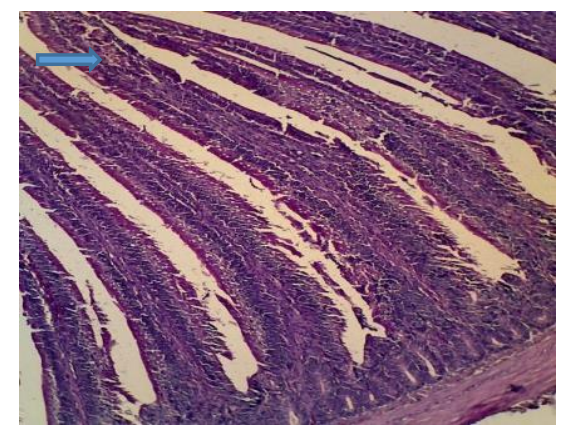

Figure 2a. Negative control. Jejunum organ. Villi appear normal, elongated, slim (blue arrow). 100x magnification.

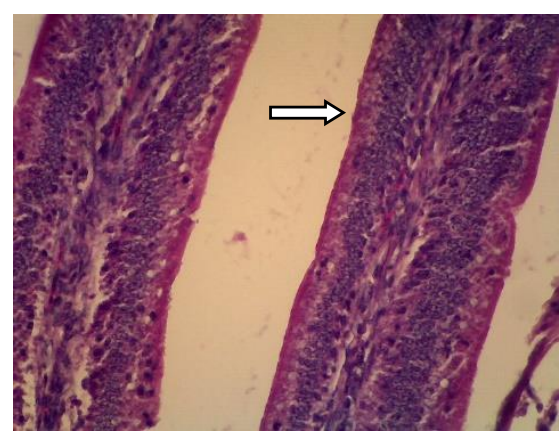

Figure 2a. Negative control. Jejunum organ. Villi appear normal, elongated, slim. Epithelium is normal (white arrow). 400x magnification. 


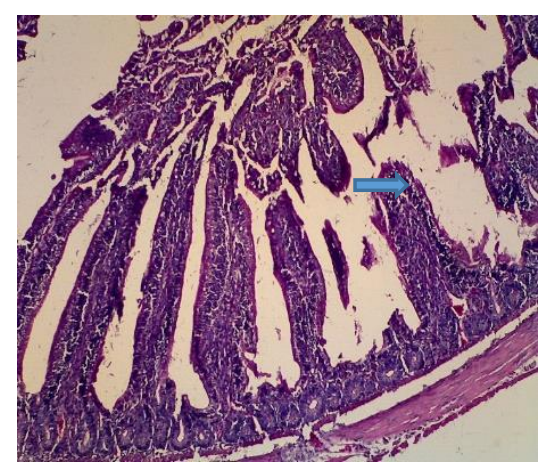

Figure 2b. Positive control. Jejunum organ. The villi are shortened and the epithelium is erosion (blue arrow). 100x magnification

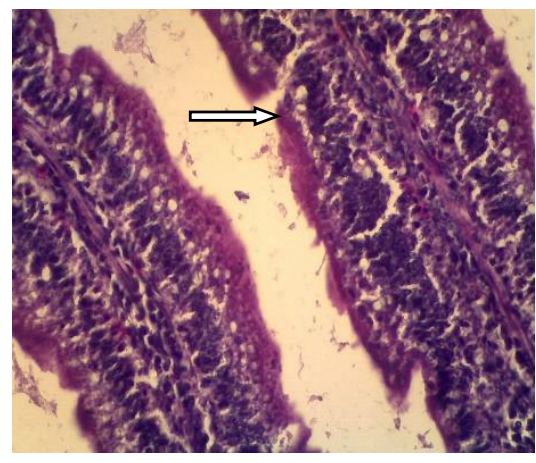

Figure 2b. Positive control. Jejunum organ. The villi are shortened and the epithelium is erosion white (white arrow). 400x magnification

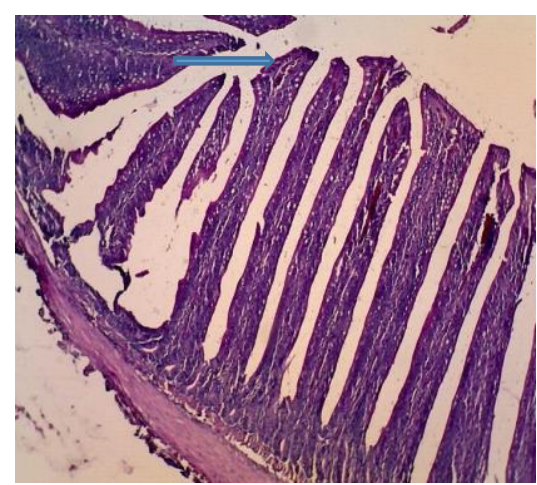

Figure 2c. T1 Treatment. Jejunum organ. Villi are elongated, partially shortened and normal (blue arrow). 100x magnification 


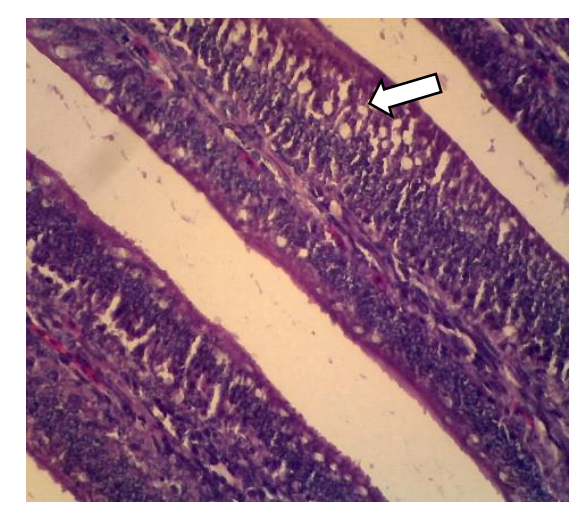

Figure 2c. T1 treatment. Jejunum organ. Epithelial and goblet hyperplasia cells (white arrow). 400x magnification

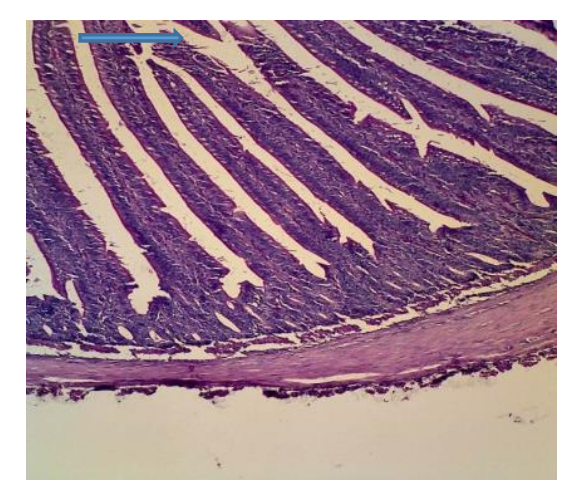

Figure 2d. T2 treatment. Jejunum organ. Elongated villi (blue arrow). 100x magnification

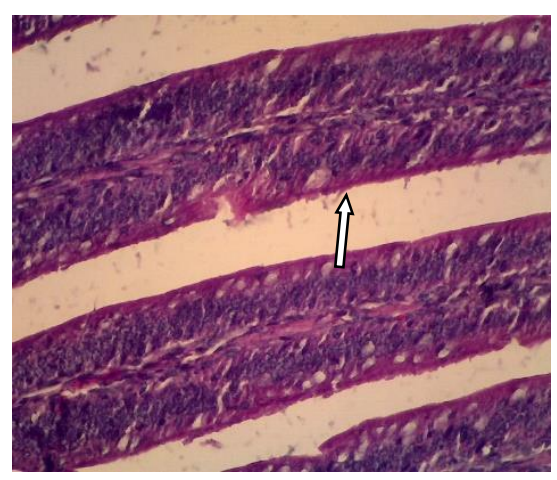

Figure 2d. T2 treatment. Jejunum organ. Epithelial and goblet hyperplasia cells (white arrow). 400x magnification 


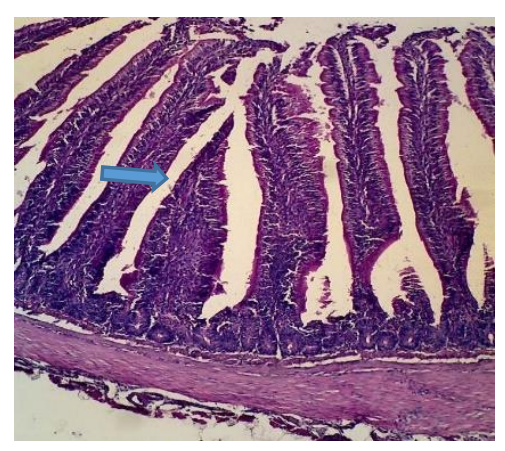

Figure 2e. T3 treatment. Jejunum organ. Villi of treatment T3 are shorter than T1 (blue arrow). 100x magnificent

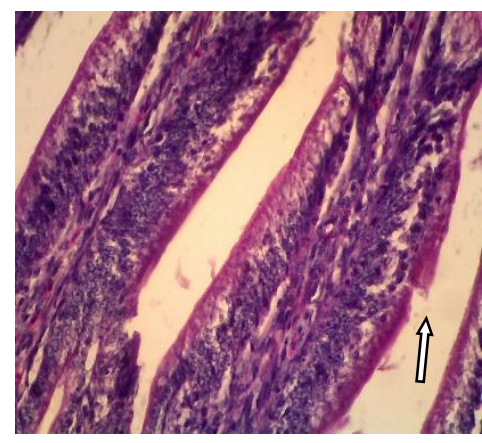

Figure 2e. T3 treatment. Jejunum organ. Epithelial erosion (white arrow) and goblet cell hyperplasia. 400x magnificent

Intestinal epithelium acts as a natural barrier to pathogenic bacteria and toxic substances in the intestinal lumen. Stressors, pathogens, and chemicals also cause interference with normal microflora or in the intestinal epithelium which can alter natural barrier permeability, facilitate invasion of pathogens and hazardous substances, modify metabolism, reduce the ability to digest and absorb nutrients, and cause chronic inflammatory processes in the mucosa intestine (Hughes, 2003; Pelicano et al., 2005). Jejunum chicken grows rapidly after birth. Morphologically, intestinal length increases rapidly and is accompanied by villous heights, in line with the rate of food absorption. In early life the main immunological development occurs in the intestine. Antigen and luminal nutrition encourage expansion and differentiation of intestinal epithelial and lymphoid tissue in regulating immune responses to environmental antigens (Schokker et al., 2010). Robusta coffee extraction contains tannin. According to a study conducted by Hughes (2003) coffee contains antinutritional factors such as non-starch polysaccharide (NSP), tannins, and alkaloids. Coffee drinks contain quite a lot of soluble dietary fiber, especially low substituted galactomannans and type II arabinogalactans.

NSPs on food are not digested which negatively affects animal performance. The negative effects of the NSP are related to viscosity, physiological and morphological effects on the digestive tract, interactions with epithelium, mucus and intestinal microflora. Dissolve NSP, increases intestinal transit time, delays gastric emptying and glucose absorption, increases pancreatic secretion, and absorption is slow. However, insoluble NSPs, such as pentosan (arabinoxylans and xylans), advantageously 
reduce transit time, increase binding of NSPs with intestinal brush borders which can increase the thickness of the water layer that does not stick around the mucosa, causing indigestion and nutrient absorption. High viscosity also increases digestion time due to increased production of intestinal volatile fatty acid (VFA). This drastic change causes the intestinal ecosystem to reduce nutrient digestibility (Sinha et al., 2011).

According to Mujtaba et al. (2017) it was shown that CGA was able to inhibit the growth of $S$. entritidis bacteria in vitro with a diameter of $17 \mathrm{~mm}$ inhibition zone. Squalamine alkaloids work by damaging the integrity of the outer membrane and cytoplasmic membrane. Alkaloids work through the following mechanism: penetrate the LPS and cause depolarization of the cytoplasmic membrane so that the cytoplasmic contents leak and bacteria will die (Cuhnie et al., 2014). Alkaloids can inhibit attachment, movement and production of free radicals by phagocytic cells. Alkaloids suppress antigen and mitogen-induced lymphocyte proliferation, Natural Killer cells, histamine release by mast cells, secretion of interleukin-1 (IL-1), prostaglandin and leukoetrin by monocytes (Barbosa-Filho et al., 2006).

Chlorogenic acid functions as an antimicrobial through the mechanism of increasing permeability of the outer membrane and plasma, resulting in loss of cell barrier function, even causing nucleotide leakage and releasing cytoplasmic macromolecules, which cause cell death (Lou et al., 2011; Mujtaba et al., 2017). Tannin can work like a siderofor to bind iron from growth media. Microorganisms that grow under aerobic conditions require iron for various functions, including reduction of ribonucleotide DNA precursors, and hem formation (Akiyama et al., 2001).

\section{CONCLUSIONS}

Based on the results of the study it can be concluded that Robusta coffee extract from Lampung can function as an antibacterial through increasing $\mathrm{CD}^{+} \mathrm{Tc}$ cells and enhancing jejunum integrity. Further research is needed to obtain the optimal dose to increase the activity of $\mathrm{CD} 8^{+}$ Tc cells and repair intestinal histopathology.

\section{DECLARATION OF CONFLICT OF INTEREST}

There was no conflict of interest between the research team

\section{ACKNOWLEDGEMENT}

Thanks to the Commodity Research Funders College in 2018, the Ministry of Research and Technology and the University of Brawijaya.

\section{REFERENCES}

Akiyama, H. (2001). Antibacterial action of several tannins against Staphylococcus aureus. Journal of Antimicrobial Chemotherapy, 48(4), 487-491. https://doi.org/10.1093/jac/48.4.487

Almeida, V., Dias, A., Bueno, C., Couto, F., Rodrigues, P., Nogueira, W., \& Faria Filho, D. (2012). Crude protein and metabolizable energy levels for layers reared in hot climates. Revista Brasileira de Ciência Avícola, 14(3), 203-208. https://doi.org/10.1590/S151 6-635X2012000300007

Barbosa-Filho, J. M., Piuvezam, M. R., Moura, M. D., Silva, M. S., Lima, K. V. B., Da-Cunha, E. V. L., Fechine, I. M., \& Takemura, O. S. (2006). Antiinflammatory activity of alkaloids: a twenty-century review. Revista Brasileira de Farmacognosia, 16(1), 109-139. https://doi.org/10.1590/S01 02-695X2006000100020

Cushnie, T. P. T., Cushnie, B., \& Lamb, A. J. (2014). Alkaloids: An overview of their antibacterial, antibioticenhancing and antivirulence activities.

International Journal of Antimicrobial Agents, 44(5), 377-386. https://doi.org/10.1016/j.ijantimi cag.2014.06.001

Gniechwitz, D., Brueckel, B., Reichardt, N., 
Blaut, M., Steinhart, H., \& Bunzel, M. (2007). Coffee dietary fiber contents and structural characteristics as influenced by coffee type and technological and brewing procedures. Journal of Agricultural and Food Chemistry, 55(26), 11027 11034. $/ 10.1021 / \mathrm{jf} 072389 \mathrm{~g}$

Hughes, R. (2003). Energy Metabolism of Chickens. In Physiological Limitations. A report for the Rural Industries Research and Development Corporation.

Jiang, J., Zenewicz, L. A., San Mateo, L. R., Lau, L. L., \& Shen, H. (2003). Activation of antigen-specific CD8 T Cells results in minimal killing of Bystander Bacteria. The Journal of Immunology, 171(11), 6032-6038. https://doi.org/10.4049/jimmunol.171 .11 .6032

Kurnianingtyas, E., Djati, M. S., \& Rifa'i, M. (2013). Aktivitas Imunomodulator Polyscias obtusa terhadap sistem imunitas pada bone marrow broiler setelah pemberian Salmonella typhimurium. The Journal of Experimental Life Sciences, 3(1), 2530. https://doi.org/10.21776/ub.jels.2 013.003 .01 .05

Lou, Z., Wang, H., Zhu, S., Ma, C., \& Wang, Z. (2011). Antibacterial activity and mechanism of action of chlorogenic acid. Journal of Food Science, 76(6), M398-M403. https://doi.org/10.1111/j. 1750-3841.2011.02213.x

Manwar, S., Rekhate, D., Joshi, M., Waghmare, S., Kuralkar, S., Saxena, M., Ravikanth, K., Maini, S., \& Choudhary, A. (2016). Production Traits optimization with polyherbal performance enhancer in layer birds. International Journal of Livestock Research, 6(12), 27. https://doi. org/10.5455/ijlr.20161116102101

Mendes, L., Silva, R., Bueno, C., Couto, F., Dias, A., Fernandes, V., \& Faria Filho, D. (2013). The inclusion of coffee in commercial layer diets. Revista
Brasileira de Ciência Avícola, 15(2), 141-144. https://doi.org/10.1590/S151 6-635X2013000200010

Meng, S., Cao, J., Feng, Q., Peng, J., \& Hu, Y. (2013). Roles of chlorogenic acid on regulating glucose and lipids metabolism: a review. EvidenceBased Complementary and Alternative Medicine, 2013, 1-11. https://doi.org/10.1155/2013/801457

Mostafa, A. A., Al-Askar, A. A., Almaary, K. S., Dawoud, T. M., Sholkamy, E. N., \& Bakri, M. M. (2018). Antimicrobial activity of some plant extracts against bacterial strains causing food poisoning diseases. Saudi Journal of Biological Sciences, 25(2), 361-366. https://doi.org/10.10 16/j.sjbs.2017.02.004

Mujtaba, A., Masud, T., Ahmad, A., Ahmed, W., Jabbar, S., \& Levin, R. E. (2017). Antibacterial activity by chlorogenic acid isolated through resin from apricot (Prunus Armeniaca L.). Pakistan Journal of Agricultural Research, 30(2), 144-148. https://doi.org/10.17582/journal. sja/2017/30.2.144.148

Muna, E., Salih, M., Zakia, A., Halima, M., Abeer, A., Ameera, M., Ali, H., \& Idris, S. (2016). Pathology of broiler chicks naturally infected with salmonella enteritidis ( $S$. enteritidis) \&amp; salmonella typhimurium ( $S$. typhimurium) during an outbreak in Sudan. Journal of Scientific Research and Reports, 10(1), 1-8. https:// doi.org/10.9734/JSRR/2016/23431

Narni-Mancinelli, E., Campisi, L., Bassand, D., Cazareth, J., Gounon, P., Glaichenhaus, N., \& Lauvau, G. (2007). Memory CD8+ $\mathrm{T}$ cells mediate antibacterial immunity via CCL3 activation of TNF/ROI+ phagocytes. Journal of Experimental Medicine, 204(9), 2075-2087. https://doi.org/10.1084/jem.20070204

Oykhman, P., \& Mody, C. H. (2010). Direct microbicidal activity of Cytotoxic $\mathrm{T}$ Lymphocytes. Journal of Biomedicine 
and Biotechnology, 2010, 1-9. https://doi.org/10.1155/20 10/249482

Pelicano, E., Souza, P., Souza, H., Figueiredo, D., Boiago, M., Carvalho, S., \& Bordon, V. (2005). Intestinal mucosa development in broiler chickens fed natural growth promoters. Revista Brasileira de Ciência Avícola, 7(4), 221-229. https://doi.org/10.1590/S1516-635X2 005000400005

Saeed, M., Naveed, M., BiBi, J., Ali Kamboh, A., Phil, L., \& Chao, S. (2019). Potential nutraceutical and food additive properties and risks of coffee: a comprehensive overview. Critical Reviews in Food Science and Nutrition, 59(20), 3293-3319. https://doi. org/10.1080/10408398.2018.1489368

Schokker, D., Peters, T. H. F., Hoekman, A. J. W., Rebel, J. M. J., \& Smits, M. A. (2012). Differences in the early response of hatchlings of different chicken breeding lines to Salmonella enterica serovar Enteritidis infection. Poultry Science, 91(2), 346-353. https://doi.org/10.3382/ps.2011-01758 Schokker, Dirkjan, Smits, M. A., Hoekman, A. J. W., Parmentier, H. K., \& Rebel, J. M. J. (2010). Effects of Salmonella on spatial-temporal processes of jejunal development in chickens. Developmental \& Comparative Immunology, 34(10), 1090-1100. https://doi.org/10.1016/j.dci.2010.05.013

Shah, D. H., Casavant, C., Hawley, Q., Addwebi, T., Call, D. R., \& Guard, J. (2012). Salmonella Enteritidis strains from poultry exhibit differential responses to acid stress, oxidative stress, and survival in the egg albumen. Foodborne Pathogens and Disease, 9(3), 258-264. https:// doi.org/10.1089/fpd.2011.1009

Sinha, A. K., Kumar, V., Makkar, H. P. S., De Boeck, G., \& Becker, K. (2011). Non-starch polysaccharides and their role in fish nutrition - A review. Food Chemistry, 127(4), 1409-1426. https://doi.org/10.1016/j.foodchem.20 11.02.042 